\title{
Classification of middle fossa floor dehiscence syndromes
}

\author{
Kunal Gupta, MD, PhD, ${ }^{1}$ Hatem A. Sabry, MD, ${ }^{1,2}$ Aclan Dogan, MD, ${ }^{1}$ Nicholas D. Coppa, MD, ${ }^{1}$ \\ Sean McMenomey, MD, ${ }^{3}$ Johnny B. Delashaw, MD, ${ }^{4}$ and Ahmed M. Raslan, MD ${ }^{1}$

\begin{abstract}
${ }^{1}$ Department of Neurological Surgery, Oregon Health \& Science University, Portland, Oregon; ${ }^{2}$ Department of Neurological Surgery, Ain Shams University, Cairo, Egypt; ${ }^{3}$ Department of Otolaryngology, New York University, New York, New York; and ${ }^{4}$ Neurosurgery, Neuroscience Institute, Swedish Medical Center, Seattle, Washington
\end{abstract}

\begin{abstract}
OBJECT Middle fossa floor dehiscence (MFFD) can present as multiple syndromes depending on dehiscence location, tissue herniation, and dural integrity. The authors propose a classification system for MFFD with the potential to guide clinical decision making.

METHODS A retrospective analysis of the electronic medical records (years 1995-2012) of patients who had undergone temporal craniotomy for the surgical repair of an MFFD syndrome at a single institution was undertaken. Reviewed data included demographic, operative, presentation, and outcome details. Middle fossa floor dehiscence was classified as follows: Class A, bony dehiscence without herniation of the brain and/or meninges; Class $\mathrm{B}$, herniation of the brain and/or meninges through the middle fossa floor without CSF leakage; Class C, dehiscence with CSF leakage without meningitis; or Class $D$, dehiscence with meningitis.
\end{abstract}

RESULTS Fifty-one patients, 22 males and 29 females, were included in the analysis. The mean age was $48.7 \pm 15.5$ years, mean body mass index was $32.65 \pm 6.86 \mathrm{~kg} / \mathrm{m}^{2}$, and mean symptom duration was $33 \pm 42$ months. Seven patients underwent repeat surgery for symptomatic recurrence; therefore, there were 58 surgical encounters. Repair included bony reconstruction with hydroxyapatite with or without resection of encephaloceles and/or repair of a dural defect. According to the MFFD classification system described, 15, 8, 27, and 8 cases were categorized as Class A, B, C, and $\mathrm{D}$, respectively. The prevalence of hearing loss was $87 \%, 63 \%$, and $70 \%$ in Classes A, B, and C, respectively. Vestibular symptoms were more prevalent in Class A. Seven patients reported persistent symptoms at the last follow-up. Transient complications were similar in each classification (13\%-25\%), and a single permanent complication related to anesthesia was observed. There were no mortalities or severe neurological morbidities in the series.

CONCLUSIONS Middle fossa floor dehiscence has a spectrum of clinical presentations. A classification system may help to clarify the diagnosis and guide therapy. Surgery, the mainstay of treatment, is safe and well tolerated.

http://thejns.org/doi/abs/10.3171/2014.11.JNS132798

KEY WORDS middle fossa floor dehiscence; Tullio's phenomenon; surgical stratification; surgical outcomes; surgical technique

$\mathrm{M}$ IDDLE fossa floor dehiscence (MFFD) has distinctly different presentations that include a range of syndromes and clinical symptoms. Middle fossa floor compromise can be spontaneous or occur secondary to accompanying disease processes, such as trauma, otitis media, inflammation, malignancy, cholesteatoma, and radiation therapy. The etiopathogenesis of spontaneous MFFD is widely debated, and several theories have been proposed. Spontaneous anterior cranial floor dehiscence and CSF leakage have been associated with empty sella syndrome and benign intracranial hy- pertension. ${ }^{18}$ These factors are similarly associated with a female predominance and an increased body mass index (BMI), which have also been associated with MFFD. 3,5,9,12 Other proposed hypotheses include congenital erosion of the middle fossa floor during pneumatization of the middle ear and mastoid air cells, ${ }^{14,19}$ as well as atrophy over years of normal CSF pulsation. ${ }^{16}$ Surgical repair has been described $^{7,12,13}$ and includes a range of procedures involving resection of the encephalocele, dural repair, and plugging of the bony dehiscence.

A wide range of clinical presentations has been de-

ABBREVIATIONS BMI = body mass index; MFFD = middle fossa floor dehiscence; OHSU = Oregon Health \& Science University. SUBMITTED December 17, 2013. ACCEPTED November 4, 2014.

INCLUDE WHEN CITING Published online January 2, 2015; DOI: 10.3171/2014.11.JNS132798.

DISCLOSURE The authors report no conflict of interest concerning the materials or methods used in this study or the findings specified in this paper. 
scribed, including auditory symptoms such as tinnitus or hearing loss; vestibular symptoms such as disequilibrium, vertigo, and Tullio's phenomenon; CSF leakage; and meningitis. ${ }^{11,12}$ Tullio's phenomenon refers to sound-evoked oscillopsia and vertigo and has been associated with compromise of the middle fossa floor over the semicircular canals. ${ }^{15,20,21}$

The myriad presentations of MFFD, each with its own signs, symptoms, and surgical repairs, have been described as separate clinical entities and often in small series. ${ }^{1,2,4,6,7,17}$ Here, we analyze a relatively large series of MFFD cases at a single tertiary care center and propose a novel classification scheme that encompasses all syndromes involving dehiscence of the middle fossa floor. We subsequently correlate the clinical presentations with surgical findings, details of operative repair, and postoperative courses.

\section{Methods}

We undertook a retrospective analysis of all patients at Oregon Health \& Science University (OHSU), a tertiary care referral center, who required transcranial surgical repair of MFFD. Investigators reviewed electronic medical records of patients who had been admitted under the adult neurosurgery service between January 1995 and June 2012. All data were anonymized. Patients with a history of chronic otitis media, temporal bone neoplasia, and head and/or neck irradiation were excluded from analysis. Extracted data were analyzed for demographics, including patient age, sex, and BMI; clinical features, including signs and symptoms at presentation and duration of symptoms; and features of surgical repair and postoperative course, including duration of inpatient stay, outcomes, and complications.

Middle fossa floor dehiscence can present with multiple syndromes of signs and symptoms. Cases requiring surgical repair of MFFD were retrospectively classified according to the location of the dehiscence, tissue herniation, and dural integrity as follows: Class A, bony dehiscence without herniation of the brain and/or meninges; Class $\mathrm{B}$, herniation of the brain and/or meninges through the middle fossa floor without CSF leakage; Class C, dehiscence with CSF leakage without meningitis; and Class $\mathrm{D}$, dehiscence with meningitis. Electronic medical records were reviewed and subsequently analyzed for MFFD classification (Fig. 1).

Data were analyzed using Fisher's exact test and are presented as the mean \pm standard deviation.

\section{Results \\ Demographics}

Fifty-eight cases of MFFD repair were identified in 51 patients based on CT identification of symptomatic dehiscence in the tegmen of the middle fossa (Fig. 2). The mean patient age was $48 \pm 15$ years (range 11-79 years), and the mean BMI was $32.65 \pm 6.86 \mathrm{~kg} / \mathrm{m}^{2}$. Seven patients underwent surgical repair for symptomatic recurrence, 3 (2 women) for symptomatic ipsilateral recurrence and 4 (2 women) for surgical repair of MFFD to the contralateral side. Of the 58 surgical cases, 25 were performed in men and 33 in women. Thirty-two procedures were right-sided. These data reflect a female predominance and increased BMI (Table 1), as reported among those suffering from MFFD., $, 5,12$

\section{Clinical Features}

For Classes A, B, C, and D, respectively, there were 15, 8,27 , and 8 cases (total 58 cases). The mean age in years was $44.5 \pm 13.5,50 \pm 22,49.7 \pm 17$, and $51.5 \pm 11$, respectively. The percentage of females in each respective class was $53.3 \%, 62.5 \%, 55.6 \%$, and $62.5 \%$. The mean BMI in each respective class was $31.2 \pm 4.3,33.5 \pm 12.8,33.7 \pm$ 5.9 , and $30.1 \pm 7.0 \mathrm{~kg} / \mathrm{m}^{2}$. Signs and symptoms at initial presentation in each respective class were as follows: hearing loss $87 \%, 63 \%, 70 \%$, and $63 \%(\mathrm{p}=0.34)$; vertiginous symptoms (dizziness, nausea, vertigo) 53\%, 13\%, 7.4\%, and $0 \%(\mathrm{p}=0.0016)$; tinnitus $27 \%, 13 \%, 7.4 \%$, and $0 \%(\mathrm{p}$ $=0.79)$; Tullio's phenomenon 53\%, $0 \%, 3.7 \%$, and $0 \%(\mathrm{p}<$ $0.001)$; pain $7 \%, 25 \%, 11 \%$, and $25 \%(\mathrm{p}=0.497)$; middle ear effusion $0 \%, 25 \%, 30 \%$, and $13 \%(\mathrm{p}=0.0345)$; ear pressure $33 \%, 0 \%, 19 \%$, and $25 \%(\mathrm{p}=0.332)$; CSF leakage $0 \%, 0 \%, 63 \%$, and $38 \%(\mathrm{p}<0.001)$; and meningitis $0 \%, 0 \%, 0 \%$, and $100 \%(\mathrm{p}<0.001)$. The mean duration of symptoms prior to initial presentation was $37 \pm 54,28 \pm$ $19,42 \pm 48$, and $11 \pm 11$ months (p < 0.003; Fig. 3).

\section{Surgical Repair}

In all cases, surgical repair was performed via craniotomy. Thirty-one cases underwent resection of an encephalocele. For Classes A, B, C, and D, respectively, $0 \%$, $75 \%, 70 \%$, and $75 \%$ of cases underwent resection of an encephalocele. Thirty-eight cases underwent dural repair. For Classes A, B, C, and D, respectively, $7 \%$ and $0 \%$ (7\% total), $38 \%$ and $38 \%$ (76\% total), $41 \%$ and $52 \%$ (93\% total), and $50 \%$ and $25 \%$ (75\% total) of cases underwent primary and secondary repair. Bony repair, as described by Gubbels et al., was performed in 38 cases in the present study; ${ }^{7}$ for Classes A, B, C, and D, respectively, $60 \%, 50 \%, 70 \%$, and $75 \%$ of cases (Fig. 4). The surgical technique for middle fossa floor repair is described elsewhere.

\section{Postoperative Course}

The average inpatient stay for Classes A, B, C, and $\mathrm{D}$ were $4 \pm 1.9,4.3 \pm 1.5,5.2 \pm 2.4$, and $4.6 \pm 1.5$ days. Four patients were lost to follow-up, but most patients had resolution of symptoms by 6-8 weeks' follow-up. In Class A cases, there were 2 complications, corneal abrasion and CSF leakage-induced headache, the latter requiring a blood patch. At follow-up, the patient in 1 case had no change in the preoperative symptoms of vertigo, headache, and disequilibrium. The patients in 2 cases had worsened headaches, and 1 of these cases underwent repeat surgery with good resolution of symptoms. In Class B cases, 1 patient had hyponatremia, which resolved with fluid restriction; 1 patient required washout for acquired infection; and 1 patient reported headache after CSF drainage. In Class $\mathrm{C}$ cases, 6 patients had perioperative complications, including traumatic bladder catheterization, corneal abrasion, and dental damage from intubation; 

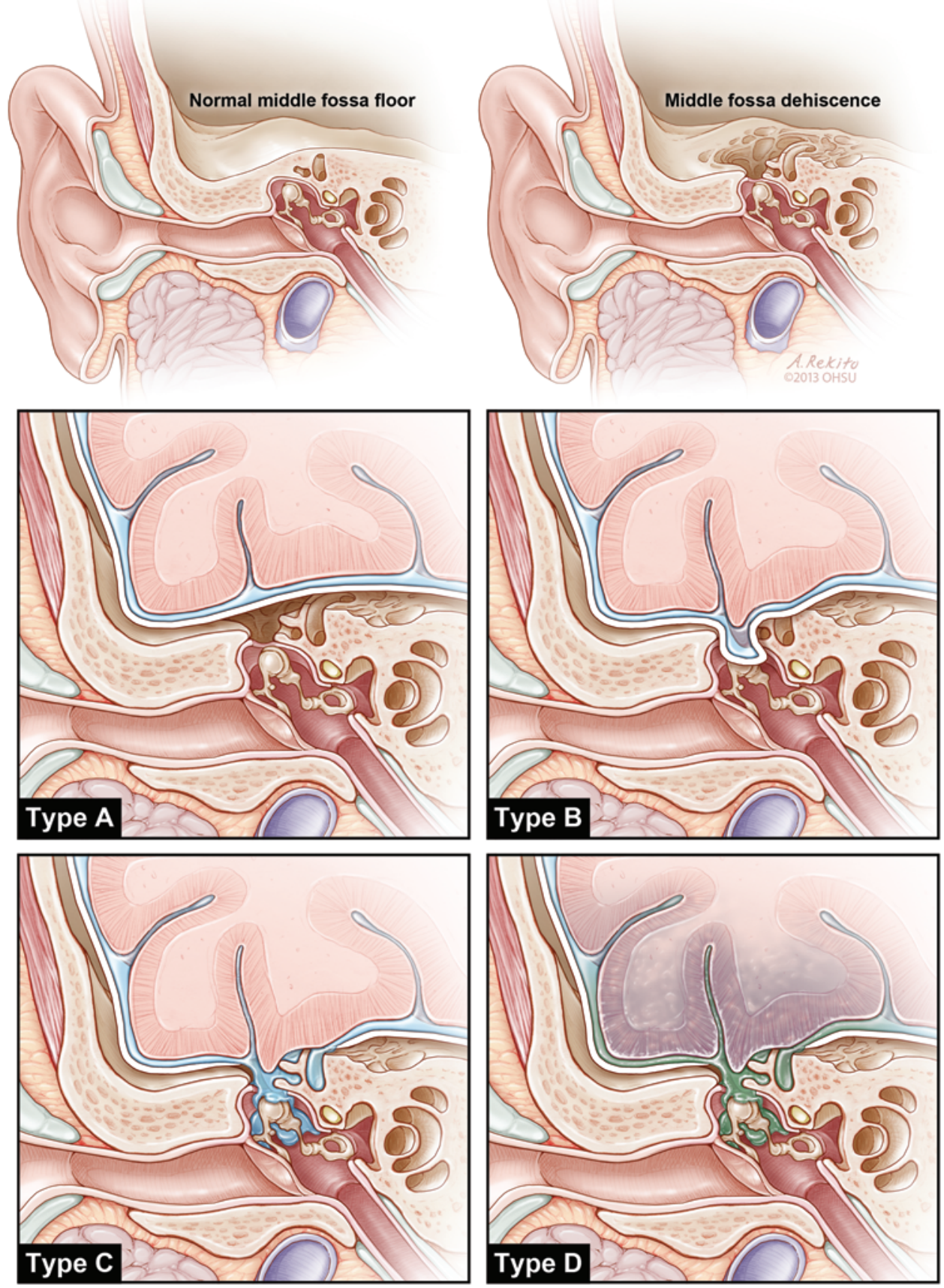

FIG. 1. Artist's representation of MFFD syndrome classifications: Class A, bony dehiscence without herniation of the brain and/ or meninges; Class B, herniation of the brain and/or meninges through the middle fossa floor without CSF leakage; Class C, dehiscence with CSF leakage without meningitis; and Class D, dehiscence with meningitis. Copyright Andy Rekito. Published with permission. Figure is available in color online only.

the dental injury was considered a permanent perioperative complication. Three patients demonstrated signs of hemifacial weakness, which resolved in all cases prior to discharge. One patient incurred a left temporal contusion and transient aphasia, which completely resolved 7 days after surgery. In 2 cases, CSF rhinorrhea persisted postoperatively and resolved prior to discharge. At follow-up, 1 patient reported ear pain, which subsequently resolved;
1 patient reported continued postoperative headache; and 2 patients reported continued CSF rhinorrhea. In Class D cases, 2 patients had postoperative headaches that resolved on their own, although 1 patient required lumbar drain insertion and blood patch for CSF leakage. This patient also later developed bone flap infection requiring explantation. At follow-up, 2 patients reported continued ear fullness and disequilibrium. Complications were similar among 

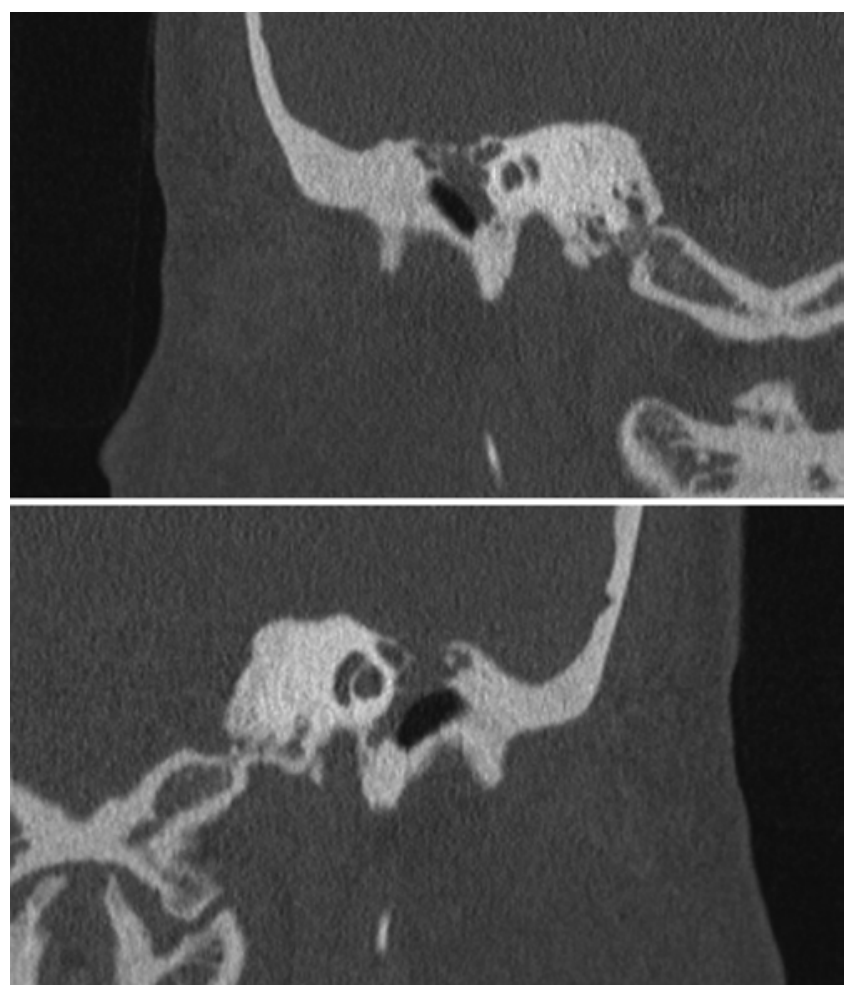

FIG. 2. Fine-cut CT scan of right (upper) and left (lower) tegmen dehiscence.

the different syndrome classes, with $13 \%, 25 \%, 22 \%$, and $25 \%$ with transient complications for Classes A-D, respectively. Permanent complication was rarely encountered, with only a single permanent complication in a patient in Class C, which was attributable to intubation. Data on complications and outcomes are expressed as percentages of the total for each class in Table 2.

Of the recurrent surgeries, 2 were performed in a patient with Class A MFFD syndrome, and both were ipsilateral recurrences. No repeat surgeries were performed in patients with Class B syndrome. Four surgeries were repeated in patients with Class $\mathrm{C}$ syndrome -3 for contralateral recurrence and 1 for ipsilateral recurrence. In Class $\mathrm{D}$ there was 1 contralateral recurrence that presented as Class $\mathrm{C}$ dehiscence. The presence of bilateral disease in multiple patients within the sampled population implicates MFFD as a progressive disorder of the intracranial space. Of the 3 cases that required repeat surgery for ipsilateral recurrence, the initial surgical repairs performed were fascial repairs rather than the bony repair described by Gubbels et al. ${ }^{7}$ These patients went on to receive the described repair, and none had a subsequent recurrence. One Class $\mathrm{C}$ case that underwent bony repair had a recurrent symptomatic CSF leak, which was successfully treated with CSF diversion. At follow-up, the majority of cases had successful resolution of symptoms.

\section{Discussion}

Middle fossa floor dehiscence presents in different ways, and these presentations are in fact a continuum of severity even though they tend to be described as separate entities. We have developed a classification system that accounts for the spectral nature of the dehiscence.

Middle fossa floor dehiscence can be spontaneous or occur secondary to accompanying disease processes. Causes of acquired MFFD include trauma, inflammatory conditions, malignancy, and radiotherapy. ${ }^{12}$ Many theories account for the origin of spontaneous MFFD, including excessive resorption of bone by normal-pressure CSF pulsation, ${ }^{16}$ which can be associated with high-pressure CSF pulsation in benign intracranial hypertension, ${ }^{18}$ and dehiscence that occurs during pneumatization of the middle ear and mastoid air cells. ${ }^{19}$ In surgery, a variety of MFFD pathologies are encountered, with variation in the extent of bone disease and involvement of the dura mater and brain parenchyma. These include bone dehiscence, prolapse of temporal lobe to dural compromise, and frank meningitis. Similarly, the clinical presentation of patients with similar pathologies varies widely, from auditory loss to ascending CNS infection. In the present study, we present MFFD syndromes as a continuum reflecting both the extent of disease and correlation with clinical presentation.

Interestingly, features of the initial clinical presentation can be clustered by classification. Ipsilateral hearing loss was not diagnostic of any particular class and was a prominent presentation feature of each class. Vestibuloauditory symptoms were prominent presenting features of Class A and were significantly less represented in Classes B, C, and D. These symptoms include vertiginous symptoms such as dizziness, vertigo, and nausea; tinnitus; ear pressure; and Tullio's phenomenon. ${ }^{21}$ It is possible that periodic or pulsatile encroachment into the middle ear in Class A produces these symptoms, which are not featured in the other classes because of persistent mass effect from prolapsed meninges and brain parenchyma present in Classes B-D. Patients in Class A underwent surgical intervention based on a clinical review at OHSU for the

TABLE 1. Patient demographics by MFFD classification

\begin{tabular}{|c|c|c|c|c|c|}
\hline \multirow[b]{2}{*}{ Variable } & \multicolumn{4}{|c|}{ MDDF Syndrome Class } & \multirow[b]{2}{*}{ Overall } \\
\hline & $A$ & B & C & $D$ & \\
\hline No. of cases & 15 & 8 & 27 & 8 & 58 \\
\hline$\%$ Males & 46.7 & 37.5 & 44.4 & 37.5 & 43.1 \\
\hline$\%$ Females & 53.3 & 62.5 & 55.6 & 62.5 & 56.9 \\
\hline Mean age (yrs) & $44.5 \pm 13.5$ & $50 \pm 22$ & $49.7 \pm 17$ & $51.5 \pm 11$ & $48 \pm 15.0$ \\
\hline Mean BMI $\left(\mathrm{kg} / \mathrm{m}^{2}\right)$ & $31.2 \pm 4.3$ & $33.5 \pm 12.8$ & $33.7 \pm 5.9$ & $30.1 \pm 7$ & $32.65 \pm 6.9$ \\
\hline Duration of symptoms (mos) & $37 \pm 54$ & $28 \pm 19$ & $42 \pm 48$ & $11 \pm 11$ & $32.6 \pm 42.5$ \\
\hline
\end{tabular}




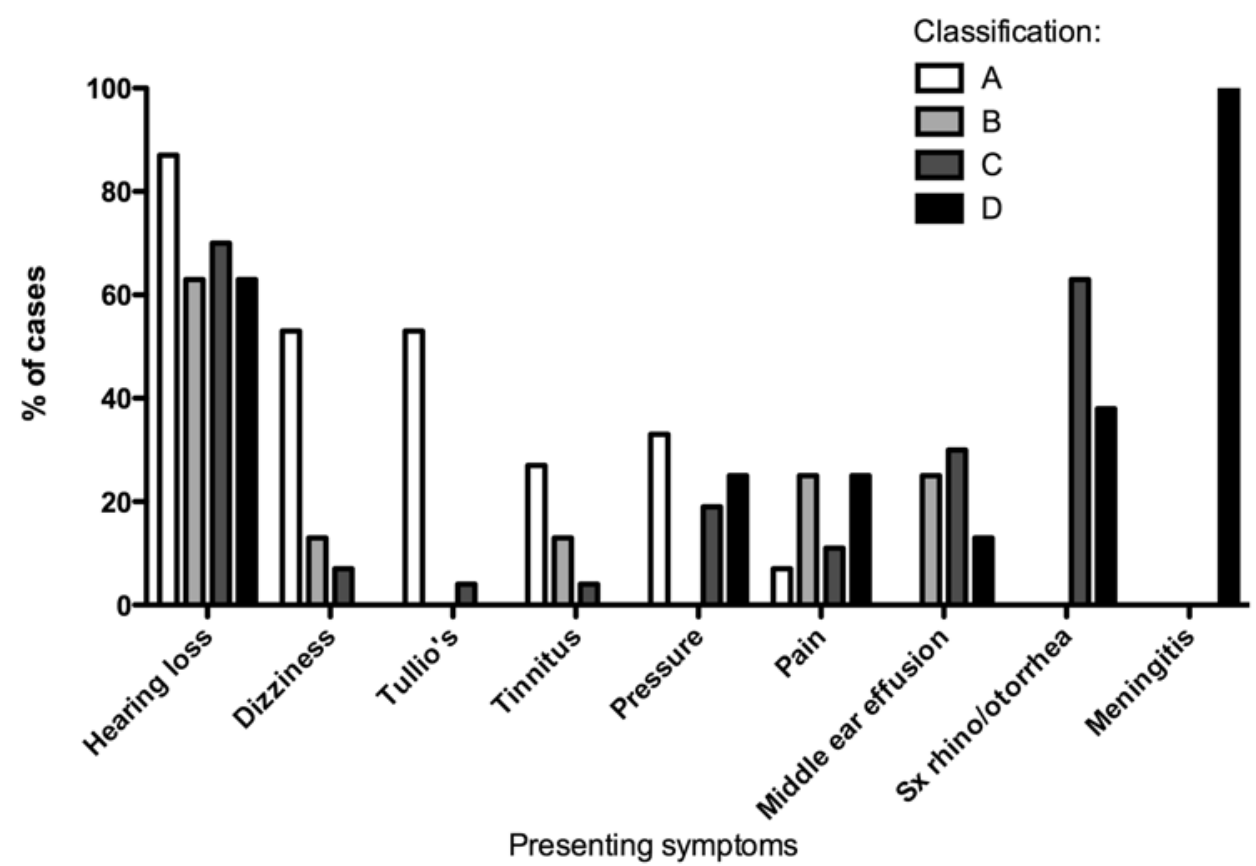

FIG. 3. Presenting symptoms for each MFFD classification. Auditory and vestibular symptoms were more prevalent in patients with Class A MFFD syndrome. Patients with Class B syndrome underwent resection of an encephalocele, and patients in Class $C$ most often presented with CSF leakage. Patients with MFFD syndrome Class D most often presented with meningitis. rhino = rhinorrhea; Sx = symptoms.

aforementioned symptoms after conservative therapy at either OHSU or a referring institution had failed. The mean symptomatic period in patients with MFFD Class A was more than 3 years. Based on the severity and duration of symptoms in the presence of an anatomical defect, we offered surgical intervention to select cases with good results. The conservative management failure rate cannot be determined based on a retrospective analysis of surgical cases. Furthermore, conservative therapy trials cannot be performed in Classes $\mathrm{C}$ and $\mathrm{D}$ because of the risk of

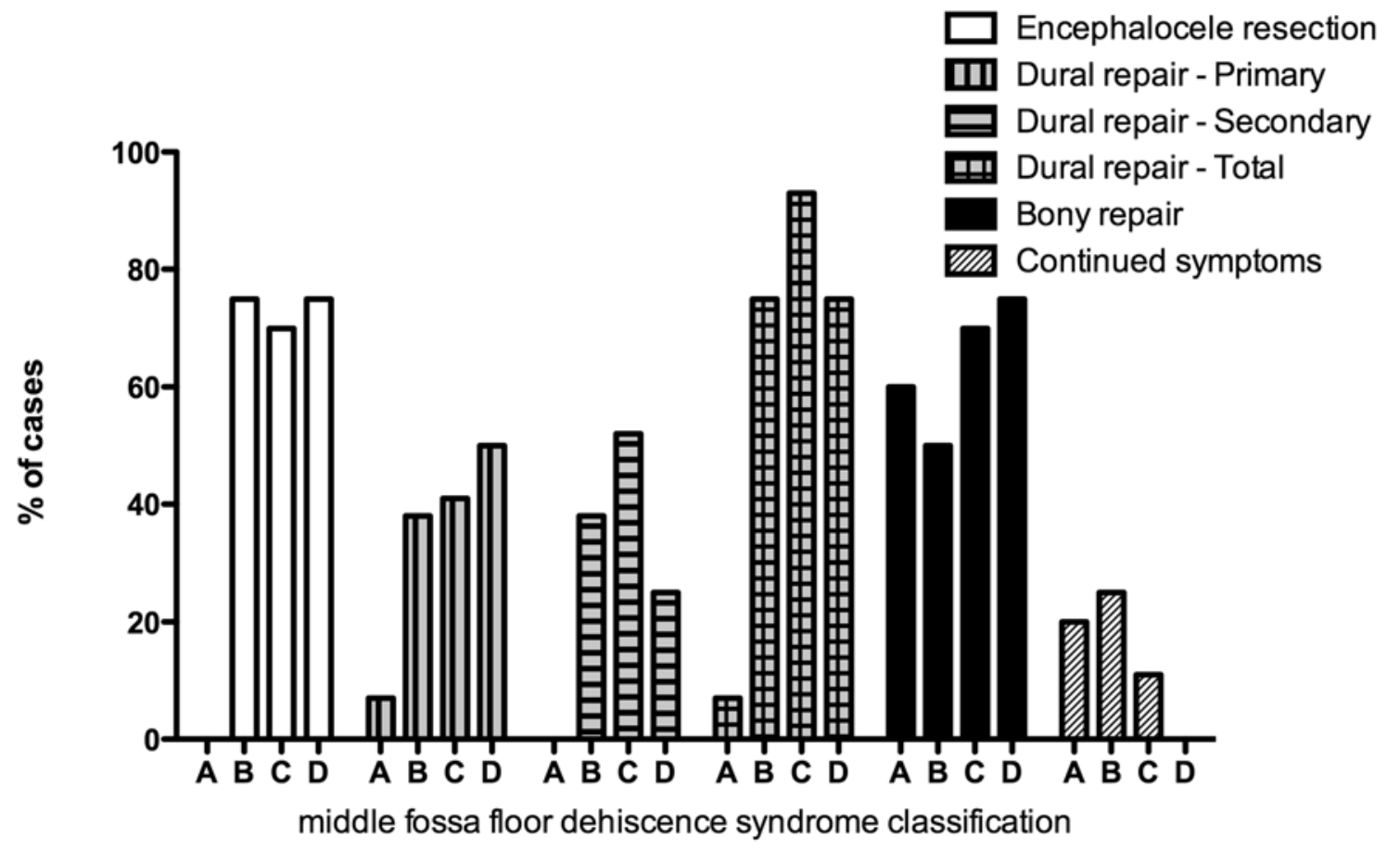

FIG. 4. Characteristics of surgical repair of MFFD syndromes. A greater-than-expected number of cases in Class B required dural repair, with the most dural repairs required in Class $C$, as expected. In certain cases in Class D, dural repair was not possible given the extent of injury to the dura. 
TABLE 2. Postoperative course in patients with MFFD

\begin{tabular}{|c|c|c|c|c|c|c|c|}
\hline $\begin{array}{l}\text { MFFD } \\
\text { Class }\end{array}$ & $\begin{array}{l}\text { No. of Surgical } \\
\text { Cases }\end{array}$ & $\begin{array}{l}\text { Mean Inpatient } \\
\text { Stay (days) }\end{array}$ & $\begin{array}{l}\text { No. w/ Ipsilat } \\
\text { Recurrence }\end{array}$ & $\begin{array}{l}\text { No. w/ Contralat } \\
\text { Recurrence }\end{array}$ & $\begin{array}{l}\text { No. of Transient } \\
\text { Complications (\%) }\end{array}$ & $\begin{array}{l}\text { No. of Permanent } \\
\text { Complications (\%) }\end{array}$ & $\begin{array}{l}\text { No. of Persistent } \\
\text { Symptoms (\%) }\end{array}$ \\
\hline A & 15 & $4.0 \pm 1.9$ & 2 & 0 & $2(13)$ & $0(0)$ & $3(20)$ \\
\hline B & 8 & $4.3 \pm 1.5$ & 0 & 0 & $2(25)$ & $0(0)$ & $2(25)$ \\
\hline C & 27 & $5.2 \pm 2.4$ & 1 & 3 & $6(22)$ & $1(4)$ & $3(11)$ \\
\hline$D$ & 8 & $4.6 \pm 1.5$ & 0 & 1 & $2(25)$ & $0(0)$ & $0(0)$ \\
\hline Total & 58 & $4.7 \pm 2.1$ & 4 & 4 & $12(21)$ & $1(2)$ & $8(14)$ \\
\hline
\end{tabular}

meningitis or the risk to life posed by meningitis, respectively. While a trial of conservative treatment could be considered in Class A and possibly in Class B, prospective data collection would be required. Ear pain featured more prominently in Classes B, C, and D. Symptomatic CSF leakage, either rhinorrhea or otorrhea, featured more prominently in Classes C and D. Meningitis was the diagnostic feature of Class D, which was probably attributable to ascending infection due to CSF leakage, given that dural compromise was found at surgery in nearly all cases. Cerebrospinal fluid leakage is by definition the hallmark of Class C but was not universally present in Class D, perhaps because dural scarring associated with meningitis in Class D prevented further CSF leaks. Duration of symptoms prior to presentation and surgical intervention were shortest in patients with MFFD Class D.

At surgical repair, meningoencephalocele resection was a prominent feature of surgery for Classes B, C, and D, and dural involvement may represent a source of local pain at presentation in these classes. Surprisingly, dural repair was required in many cases in Class B despite the absence of evidence of symptomatic CSF leakage. This was probably attributable to tamponade of the CSF leak by herniated brain parenchyma. Dural repair was a significant part of almost all Class $\mathrm{C}$ cases and was performed both primarily and with grafting. Dural repair was comparatively less represented in Class D, because of dural scarring or extensive disease preventing closure of the dural defect evidenced at surgery. The bony dehiscence was repaired in over half of all cases using the methodology described by Gubbels et al. ${ }^{7}$ and was similarly represented in all dehiscence classes. Notably, the present study is limited by the risk of bias inherent to retrospective cohort investigations. The cases were taken from a review of 18 years of data at 1 institution. Procedures were performed by 4 surgeons with varying practices in terms of immediate postoperative management, which also subjects the results to the risk of selection bias. Furthermore, cases involving middle fossa craniotomy for the repair of tegmen dehiscence were selected for inclusion in the study. Transsphenoidal cases were excluded because of their comparative rarity; only a single case was performed at our institution during the investigated time period. Various centers have published individual case reports and small series on the successful treatment of transsphenoidal encephaloceles through a combination of transpalatal/transnasal and transcranial approaches..$^{8,10}$

The classification system described herein has multiple clinical benefits and utility. It clusters syndromes of clinical presentation and correlates these similar presenta- tions with findings at surgical repair. This has the benefit of allowing clinicians to predict surgical requirements when eliciting a clinical history and can guide radiological investigations. Indeed, several cases in this large series were misdiagnosed as cholesteatoma and underwent delayed diagnosis as an MFFD syndrome; in these cases beta-2 transferrin testing of otorrhea was nondiagnostic. Our classification system has the potential to shorten the time to diagnosis based on the early recognition of clusters of clinical symptoms. The classification system also describes a logical progression of pathology from pure bony dehiscence, prolapse of dura and brain, dural compromise, and subsequent ascending infection. Moreover, analysis of cases revealed that patients presenting with Class $C$ often presented with contralateral Class $\mathrm{C}$ disease, suggesting both a global intracranial disease process affecting the middle fossa bilaterally and gradual progression as described. An additional benefit of this syndrome classification is its potential to facilitate communication between referring and tertiary care centers. Classes A and B can be treated in outpatient elective procedures; however, Classes $\mathrm{C}$ and $\mathrm{D}$ are more emergent and require appropriate inpatient observation and care.

\section{Conclusions}

In summary, we describe a novel classification system for MFFD syndromes and demonstrate the correlation between clustered clinical syndromes and surgical findings. We describe the findings and clinical course of these different presentations and demonstrate that surgical management is well tolerated, safe, and effective. This classification system has the potential to guide investigation, diagnosis, and subsequent management of patients presenting with MFFD syndromes.

\section{Acknowledgments}

We thank Shirley McCartney, $\mathrm{PhD}$, for editorial assistance, and Andy Rekito, MS, for illustrative assistance.

\section{References}

1. Alexander NS, Chaaban MR, Riley KO, Woodworth BA: Treatment strategies for lateral sphenoid sinus recess cerebrospinal fluid leaks. Arch Otolaryngol Head Neck Surg 138:471-478, 2012

2. Arai A, Mizukawa K, Nishihara M, Fujita A, Hosoda K, Kohmura E: Spontaneous cerebrospinal fluid rhinorrhea associated with a far lateral temporal encephalocele-case report. Neurol Med Chir (Tokyo) 50:243-245, 2010

3. Dutt SN, Mirza S, Irving RM: Middle cranial fossa approach 
for the repair of spontaneous cerebrospinal fluid otorrhoea using autologous bone pate. Clin Otolaryngol Allied Sci 26:117-123, 2001

4. Dysart BR: Spontaneous cerebrospinal otorrhea. Report of a case with successful surgical repair. Trans Am Laryngol Rhinol Otol Soc 1959:381-387, 1959

5. Gacek RR, Gacek MR, Tart R: Adult spontaneous cerebrospinal fluid otorrhea: diagnosis and management. Am J Otol 20:770-776, 1999

6. Goddard JC, Meyer T, Nguyen S, Lambert PR: New considerations in the cause of spontaneous cerebrospinal fluid otorrhea. Otol Neurotol 31:940-945, 2010

7. Gubbels SP, Selden NR, Delashaw JB Jr, McMenomey SO: Spontaneous middle fossa encephalocele and cerebrospinal fluid leakage: diagnosis and management. Otol Neurotol 28:1131-1139, 2007

8. Kahyaoğlu O, Cavuşoğlu H, Müslüman AM, Kaya RA, Yilmaz A, Sahin Y, et al: Transsellar transsphenoidal rhinooral encephalocele. Turk Neurosurg 17:264-268, 2007

9. Kari E, Mattox DE: Transtemporal management of temporal bone encephaloceles and CSF leaks: review of 56 consecutive patients. Acta Otolaryngol 131:391-394, 2011

10. Kohan E, Lazareff J, Kawamoto H, Bradley JP: Successful staged correction of transsphenoidal encephaloceles. Plast Reconstr Surg 126:197-204, 2010

11. Lim ZM, Friedland PL, Boeddinghaus R, Thompson A, Rodrigues SJ, Atlas M: Otitic meningitis, superior semicircular canal dehiscence, and encephalocele: a case series. Otol Neurotol 33:610-612, 2012

12. Lundy LB, Graham MD, Kartush JM, LaRouere MJ: Temporal bone encephalocele and cerebrospinal fluid leaks. Am J Otol 17:461-469, 1996

13. Mayeno JK, Korol HW, Nutik SL: Spontaneous meningoencephalic herniation of the temporal bone: case series with recommended treatment. Otolaryngol Head Neck Surg 130:486-489, 2004

14. Merchant SN, McKenna MJ: Neurotologic manifestations and treatment of multiple spontaneous tegmental defects. Am J Otol 21:234-239, 2000
15. Minor LB, Cremer PD, Carey JP, Della Santina CC, Streubel SO, Weg N: Symptoms and signs in superior canal dehiscence syndrome. Ann N Y Acad Sci 942:259-273, 2001

16. Ommaya AK: Cerebrospinal fluid rhinorrhea. Neurology 14:106-113, 1964

17. Pelosi S, Bederson JB, Smouha EE: Cerebrospinal fluid leaks of temporal bone origin: selection of surgical approach. Skull Base 20:253-259, 2010

18. Schlosser RJ, Woodworth BA, Wilensky EM, Grady MS, Bolger WE: Spontaneous cerebrospinal fluid leaks: a variant of benign intracranial hypertension. Ann Otol Rhinol Laryngol 115:495-500, 2006

19. Schuknecht HF: [Spontaneous cerebrospinal fluid fistula in the tegmen tympani.] HNO 42:288-293, 1994 (Ger)

20. Streubel SO, Cremer PD, Carey JP, Weg N, Minor LB: Vestibular-evoked myogenic potentials in the diagnosis of superior canal dehiscence syndrome. Acta Otolaryngol Suppl 545:41-49, 2001

21. Tullio P: Das Ohr und die Entstehung der Sprache und Schrift. Berlin: Urban \& Schwarzenberg, 1929

\section{Author Contributions}

Conception and design: Raslan, Dogan. Acquisition of data: Raslan, Gupta, Dogan, Coppa, McMenomey, Delashaw. Analysis and interpretation of data: Raslan, Gupta, Sabry, Dogan. Drafting the article: Raslan, Gupta, Sabry, Dogan. Critically revising the article: Raslan, Gupta, Sabry, Dogan. Reviewed submitted version of manuscript: all authors. Approved the final version of the manuscript on behalf of all authors: Raslan.

\section{Correspondence}

Ahmed M. Raslan, Neurological Surgery, Oregon Health \& Science University, 3303 S.W. Bond Ave., CH8N, Portland, OR 97239. email: raslana@ohsu.edu. 